\title{
Pragmatics
}

GUNTER SENFT

Max Planck Institute for Psycholinguistics, Nijmegen, Netherlands

In linguistics, the study of actual language use is called "pragmatics," a term first used by Charles Morris (1938). Language use is not only dependent on linguistic, that is, grammatical and lexical, knowledge, but also on cultural, situative, and interpersonal context and convention. One of the central aims of pragmatics is to research how context and convention-in their broadest sense-contribute to meaning and understanding. Pragmatics studies language from the perspective of language users embedded in their situational, behavioral, cultural, societal, and political contexts, using a broad variety of methodologies and interdisciplinary approaches depending on specific research questions. This entry is based on the following insights:

1. Languages are used by their speakers in social interactions; they are first and foremost instruments for creating social bonds and accountability relations. The means with which languages create these bonds and relations vary across languages and cultures. Pragmatics studies these language- and culture-specific forms of language use.

2. Speech is part of the context of the situation in which it is produced; language has an essentially pragmatic character, and meaning is constituted by the pragmatic function of an utterance.

- Speakers of a language follow conventions, rules and regulations in their use of language in social interactions.

- The meaning of words, phrases, and sentences is conveyed in certain kinds of situative contexts.

- The speakers' uses of language fulfill specific functions in and for these speakers' communicative behavior.

3. Pragmatics understands and describes language as social action.

4. Core domains of pragmatics reveal that it is a "transdiscipline" within the humanities.

The structure of this entry is based on the last insight. Each section of the entry discusses some core issues of pragmatics that were introduced to the field by five other disciplines.

The International Encyclopedia of Communication Theory and Philosophy.

Klaus Bruhn Jensen and Robert T. Craig (Editors-in-Chief), Jefferson D. Pooley and Eric W. Rothenbuhler (Associate Editors).

(๑) 2016 John Wiley \& Sons, Inc. Published 2016 by John Wiley \& Sons, Inc.

DOI: 10.1002/9781118766804.wbiect165 


\section{Pragmatics and philosophy}

One of the central questions of philosophy is how we generate "meaning," and one of the tools we use to do this is language. But what do we do when we speak? In 1962 John L. Austin developed his conception of speech as action in his book How to Do Things With Words. Austin differentiates the following speech acts: A locutionary act is the act of saying something meaningful; it consists of a phonetic act (uttering noises), a phatic act (uttering words in a grammatical construction), and a rhetic act (using meaningful words). Locutionary acts are also illocutionary acts that do something in saying something (like accusing, promising, etc.); they conform to convention and have an illocutionary force which causes certain effects. Perlocutionary acts also do something by saying something (like persuading, convincing, etc.), but they produce effects on feelings or actions of the addressee(s). These three speech acts are illustrated by the following examples:

Locution: "He said to me 'kiss her!' meaning by 'kiss' kiss and referring by 'her' to her." Illocution: "He urged/advised me to kiss her."

Perlocution: "He got me to/made me kiss her."

Thus, a locutionary act (which includes the phonetic, phatic, and rhetic acts) just means saying something meaningful in its normal sense. The performance of this locutionary act involves an illocutionary act which has a certain force (like urging, advising, etc.). And the achieved effect of this illocutionary act on listeners (which has consequences for them) is the perlocutionary act.

John R. Searle (1969) systematized and formalized Austin's theory of speech acts. He understands speaking as performing illocutionary acts which have both a specific function-indicating element, the illocutionary force, and a proposition-indicating element, the propositional content. Speakers perform illocutionary acts in a rulegoverned form of behavior. Searle (1969, pp. 57-71) shows that speech acts (e.g., promising, requesting, greeting, asserting) follow constitutive rules which can be extracted from the conditions under which they are performed. Searle's rules can be summarized as follows:

- propositional content rules specify what the speech act is about;

- preparatory condition rules specify the necessary prerequisites for the speech act;

- sincerity condition rules specify whether the speech act is performed sincerely or not; and

- essential condition rules say what kind of illocutionary act the utterance is to count as.

Speech acts differ from each other, of course; Searle (1976) presents a list of the basic categories of illocutionary acts which consists of five types:

1. Representatives, like acts of asserting, reporting, stating, concluding, deducing, and describing, for example, "Obama is the 44th president of the United States." 
2. Directives, like acts of requesting, asking, ordering, commanding, begging, pleading, praying, defying, and challenging, for example, "Go home."

3. Commissives, like acts of promising, threatening, offering, and pledging, for example, "I will have written this paper by Friday next week."

4. Expressives, like acts of thanking, congratulating, apologizing, condoling, deploring, and welcoming, for example, "What a wonderful paper, Mark!"

5. Declarations, like acts of appointing, nominating, marrying, christening, excommunicating, declaring war, resigning, and firing (from employment), for example, "I now pronounce you man and wife."

Besides these five types of speech acts Searle also differentiates between direct and indirect speech acts. In the next two sentences-the first being a request and the second being a grammatical imperative-we observe a direct match between the sentence type and its illocutionary force. These two sentences illustrate direct speech acts:

"I request you to pass the salt."

"Pass the salt, please."

A sentence like

"Can you pass the salt?"

is at first sight a question. However, we all understand that this question about a specific ability of a hearer is also a request addressed to the hearer that should make him pass the salt to the speaker. This is an indirect speech act; we observe a difference between what is said and what is actually meant-or implicated-by the speaker. Pieter Seuren (2009, p. 143) points out that "indirect speech acts ... are often subject to social and/or linguistic convention, which has to be learned in order to participate adequately in a society ... [The] indirect-speech-act character is accounted for by an appeal to social, not linguistic, competence." Seuren devotes special attention to the socially binding force of speech acts and formulates the "principle of social binding," emphasizing "that language is primarily an instrument for the creation of accountability relations and not for the transfer of information" (Seuren, 2009, p. 140). Thus, speech has an eminent "social contract function."

In the mid-1970s H. Paul Grice developed his "theory of conversational implicature." In this theory the adequate reaction of an addressee hearing an indirect speech act is explained by the "cooperative principle of conversation." For Grice conversation is guided by a system of expectations-by maxims-that are mutually shared by interactants. His cooperative principle which underlies conversation runs: "Make your conversational contribution such as is required, at the state at which it occurs, by the accepted purpose or direction of the talk exchange in which you are engaged." This principle is constituted by the four maxims: quantity, quality, relation, and manner; they are defined as follows (see Grice, 1975, pp. 45-46):

With the category of quantity go the maxims: 
(1) "Make your contribution as informative as is required."

(2) "Do not make your contribution more informative than is required."

With the category of quality goes the supermaxim:

"Try to make your contribution one that is true."

and two more specific maxims:

(1) "Do not say what you believe to be false."

(2) "Do not say that for which you lack adequate evidence."

With the category relation goes the maxim:

"Be relevant."

And with the category manner goes the supermaxim:

"Be perspicuous."

and various maxims such as:

(1) "Avoid obscurity of expression."

(2) "Avoid ambiguity."

(3) "Be brief (avoid unnecessary prolixity)."

(4) "Be orderly."

All these maxims can be violated or "flouted"; however, for Grice, these four conversational maxims serve the basis for figuring out the nonliteral meaning of utterances like indirect speech acts.

\section{Pragmatics and psychology}

How do speakers of different languages refer to objects, persons, places, periods of time, and even texts or text passages? When speakers do this, they communicate in certain contexts, and these contexts shape their utterances. Natural languages are context-bound, and the subdiscipline of linguistics that concerns how languages encode features of the context of utterances is called "deixis." Thus, when someone wants to know what is meant by a sentence like "He gave me this book yesterday" she or he needs to know how this sentence is deictically anchored, that is, who uttered it, when and where, and to which book the speaker refers. Deixis is the name given to the system of indexical forms and means that make these references, and, as illustrated by the sentence above, these indexicals are characterized by the fact that their use and meaning are completely context-dependent. The most influential contribution on the topic of deixis was presented by the German psychologist Karl Bühler (1934). He differentiates between the following kinds of pointing:

- $\quad$ personal deixis (I, you, the others, etc.) 
- social deixis (mate, Sir, etc.)

- temporal deixis (now, in 1952, etc.)

- spatial deixis (here, west, left, behind, etc.)

and the following modes of pointing:

- situative deictic reference, that is, reference ad oculos (“This is our house.")

- anaphora, that is, nondeictic usage of expressions that refer to a referent mentioned earlier ("These are our children. They are cute.")

- cataphora, that is, nondeictic usage of expressions that refer to a forthcoming referent ("Here he comes, the man who scored the goal: Pelé!")

- imaginative or transposed deixis which characterizes all forms of reference in fictive contexts ("Pippi Longstocking is skylarking in her Villa Villekulla.").

Languages differ fundamentally in how they make deictic references. The linguistic means available for spatial deictic reference, for example, encompass adpositions (at, on), locatives (here, there), directionals (toward, into), positionals and motion verbs (to stand, to go), presentatives (here is, voilà) and demonstratives (this, that). If we look at demonstratives in the languages of the world, we find systems of spatial deictics that consist of two terms (English: this, these/that, those, here, there), three terms (Latin: hic, iste, ille), and more than three terms-like Daga (spoken in Papua New Guinea) with 14 terms, and Alaskan Yup'ik with over 30 terms. The use of these demonstratives is designed for recipients; their location plays a crucial role for the speaker's selection of a demonstrative.

The way in which angles are projected from the ground in order to locate the figure in an utterance plays another crucial role for spatial references. (In the sentence "The socks are in the drawer" the "socks" constitute the figure, the "drawer" constitutes the ground, and the spatial relation between the two is "being in.") There are three different frames of spatial reference (see Pederson et al., 1998):

Relative systems are viewpoint-dependent: Localizations in space are derived from the position and orientation of the speaker. The sentence

"The ball is to the right of the man."

is understood from the speaker's point of view only; it completely neglects the orientation of the man.

Absolute systems operate on absolute concepts of direction. They are based on conventionalized directions or other fixed bearings that can be derived from meteorological, astronomical, or landscape features. In these systems we find sentences like

"The ball is to the west of the man/uphill from the man/ seaward from the man."

Intrinsic systems utilize inherent, intrinsic features of an object to derive a projected region or to anchor the spatial reference to an object in these features. The sentence 
"The ball is to the man's right."

is understood as follows: A man is an object with a front and back, a left and right side assigned to it. In intrinsic systems this sentence refers to the position of the ball on the basis of the orientation of the man: The ball is at the right side of the man; the orientation of the speaker does not play any role whatsoever. However, speakers using intrinsic systems for their spatial references also refer to the same configuration with the sentence:

"The ball is to the right of the man."

Thus, languages can be ambiguous with respect to whether they use an intrinsic or a relative perspective in their spatial references. Sentences like the last one presented can only be disambiguated in the actual situation and context.

The term deixis is borrowed from the Greek word for pointing or indicating. We not only point with words, but also with gestures. Gestures accompany speech spontaneously. Besides deictic or pointing gestures we can differentiate iconic gestures which present images of concrete entities or actions, metaphoric gestures which picture abstract content (e.g., displaying an empty palm to present a problem), and beats which rhythmically accompany prosodic peaks in speech. Moreover, there are also language-like gestures, the so-called emblems like, for example, "thumbs up," which are culture-specific conventionalized signs that are meaningful with or without speech. And there are even "pragmatic" gestures which perform conventional acts (e.g., betting) in nonverbal ways (see Austin, 1962, p. 19).

We not only observe cospeech gestures which are primarily used for addressees and thus have a strong social component. There are also cothought gestures speakers produce just for themselves in problem-solving situations, especially in solving spatial visual problems, for example, in mental rotation or paper-folding tasks. Thus gesturing can support thinking. That means that language, gesture and mind are strongly interrelated. It seems that cospeech gestures are universal. However, it must be emphasized here that the ways gestures are produced can vary substantially across languages and cultures. The study of indexicals and cospeech gestures is extremely important for pragmatics because they provide direct evidence that human interaction is multimodal.

\section{Pragmatics and human ethology}

Human ethology is a subdiscipline of biology that deals among other things with the communicative functions of all kinds of expressive behavior. Among the most communicative of such behavioral signals are facial expressions. One of these signals is the "eyebrow-flash," the rapid raising of the eyebrow, a behavior documented in mother-child interactions and in situations of friendly contact establishment in many cultures. However, there are cultural differences: rapid eyebrow raising as an expression of factual "yes" occurs only in a few cultures (e.g., in Polynesia) while slow eyebrow raising as a factual "no" is restricted to some Mediterranean people. Greeting strangers 
in a friendly context with the eyebrow flash is observed in many cultures; however, in Japan it would be inappropriate for adults to greet each other in such a way. Eyebrow raising appears most frequently together with smiling and upward moving of the head. It is typically used as a ritualized form of greeting, signaling friendly openness for social contact; it contributes to establishing and maintaining a social bond between interactants (see Eibl-Eibesfeldt, 1989, pp. 452-459).

Territorial behavior of humans expressed in personal distance, posture behavior, and body motion is another means of expressing communicative and interactional signals. This behavior is different in different cultures (see Senft, 2014, pp. 83-85).

Ethologists argue that expressive movements like those just mentioned have undergone distinctive differentiation in the service of signaling in phylogenetic and cultural ritualization processes. They are usually simplified and repeated rhythmically, they get exaggerated, and they have a specific intensity. These ritualized signals make the behavior of interactants predictable. This increase of predictability of human behavior rituals provides security and order in interaction. Rituals create and stabilize social relations; they serve the functions of bonding and aggression-blocking and are central to the interaction of all living beings. Ellen B. Basso and Gunter Senft (2009, p. 1) define ritual communication as

artful, performed semiosis, predominantly but not only involving speech, that is formulaic and repetitive and therefore anticipated within particular contexts of social interaction. Ritual communication thus has anticipated (but not always achieved) consequences. As performance, it is subject to evaluation by participants according to standards defined in part by language ideologies, local aesthetics, contexts of use, and, especially, relations of power among participants.

In what follows this concept is briefly illustrated with William Labov's work on ritual insults in peer groups of black adolescents in Harlem, New York (Labov, 1972). These rituals are duels with words. Labov analyzed the complex structures of this sophisticated form of ritual communication, emphasizing that these duels strengthen solidarity between peer group members by violating American middle-class norms. They also open up sanctuaries for competition, in which individuals can test out their status with respect to the ranking of other members within the group without too much danger of being sanctioned, because of the overall tacitly understood convention that these insults are ritual ones and thus not meant personally. Possible escalations toward real forms of aggression during sessions of ritual insults can be avoided by emphasizing the nonpersonal character of the situation as a ritualized language game.

Irenäus Eibl-Eibesfeldt argues that rituals and forms of ritual communication can be referred back to so-called basic interaction strategies. He claims that all humans have a finite set of these conventionalized strategies at their disposal and assumes that these strategies are universal. Eibl-Eibesfeldt differentiates four such strategies-strategies of group maintenance and bonding, of social learning and teaching, of striving, and of fighting-and subclassifies them in a subtle way (see Eibl-Eibesfeldt, 1989, pp. 520-521). Forms of human interactive behavior vary enormously from culture to culture; they have to be learned because all members of a group have to be on common ground to interact adequately with each other. But these various strategies of social interaction share a universal pattern, based upon a universal rule system. Thus, 
the ways people in different cultures try to acquire status, get a gift from someone, invite someone, or block aggression follow in principle the same basic patterns. And therefore many rituals and forms of ritual communication can be traced back to, or at least be understood as, the differentiation of this finite set of conventionalized basic interaction strategies (see Eibl-Eibesfeldt, 1989, pp. 425-547).

\section{Pragmatics and ethnology}

One of the anthropologists whose ethnographic theory about meaning and language became extremely influential in pragmatics was Bronislaw Malinowski. For him, language in its primitive function and original form has an essentially pragmatic character. It was a mode of behavior, a mode of action in which the meaning of a word or an utterance is constituted by its function within certain contexts. He was especially interested in how the meaning of utterances can be determined in what he calls the essential primitive uses of speech: speech in action, ritual handling of words, the narrative, and "phatic communion." He defined the concept of phatic communion as a form of language use that has exclusively social bonding functions like establishing and maintaining a friendly and harmonious atmosphere in interpersonal relations, especially during the opening and closing stages of social encounters. It does not serve any purpose of communicating ideas and expressing thoughts (see Senft, 2014, pp. 104-112). However, phatic communion also has indexical functions with respect to the interactants' status and social identity and it may initiate routine exchanges that can be rich in information.

The concept of phatic communion illustrates just one aspect of Malinowski's linguistic thinking. He was also interested in universal features of language and in the interrelationship between language, culture, and cognition that is expressed in culture-specific features and phenomena of languages. This interest was shared by the linguist Franz Boas, one of Malinowski's contemporaries. Boas's student Edward Sapir took up his teacher's cautiously formulated ideas about this interrelationship and together with his student Benjamin Lee Whorf he formulated the so-called Sapir-Whorf hypothesis about linguistic relativity with which they claim to answer the question: "What is the relationship between language and thought?" Whorf came up with two versions of the linguistic relativity principle; the strong version claims that language determines thought, whereas the weak version claims that language influences thought (see Senft, 2014, pp. 113-119).

Since its publication this hypothesis-especially its strong version-has been discussed quite controversially. In the 1990s linguists and anthropologists attempted to test the weak version of the Sapir-Whorf hypothesis (see Pederson et al., 1998). Their cross-linguistic research revealed fundamental differences in how speakers of different languages refer to space. For describing these differences, the typology of spatial systems or frames of spatial reference (presented in the section on "pragmatics and psychology" above) was used. All three frames of spatial reference described above can be found in a given language, however, most languages seem to prefer one of these systems in a particular context. Based on this observation the following hypothesis 
was formulated: If speakers of a language preferentially use one reference system in a particular spatial domain, then these speakers will rely on a comparable coding system for memorizing spatial configurations and making inferences with respect to these spatial configurations in nonverbal problem-solving. A number of experiments were developed and carried out in the researched speech communities. They verify the hypothesis with respect to the interrelationship between verbal and nonverbal coding of spatial configurations. However, even with results of studies like these, it still remains somewhat problematic to argue that it is only language that influences thought in general and that this influence is unidirectional. Nevertheless, researching the relationship between language, culture, and cognition certainly is a challenging but rewarding enterprise.

Malinowski, Boas, and Sapir insisted that the use of language must be studied in its social context. Whoever wants to investigate the role of language, culture, and cognition in social interaction must know how the researched society constructs its reality. Researchers need to be on common ground with the researched communities, and this common ground knowledge is the prerequisite for any successful research within this domain. To achieve this aim, the "ethnography of speaking" approach founded by Dell Hymes provides a useful framework (see Senft, 2014, pp. 120-123). Hymes introduced the notions of speech style and speech or communicative event and argued that the meaning of an utterance can only be understood in relation to the speech event in which it is embedded. Analyses of these styles or events require the minute study of and of the interrelationship between what he called components. He grouped these components into the following eight main entries that could be remembered with the acronym SPEAKING: situations, participants, ends (goals), act sequences (message form and content), keys (manner in which something is said), instrumentalities (forms of speech), norms, and genres of speech styles and speech events. Hymes understood this list of components as a first set of questions and possibilities in the study of "ways of speaking" in specific speech communities with the aim of revealing the rules that guide the communicative behavior of members of the researched community and thus exploring the communicative competence of its members. In 1983 Joel Sherzer provided an exemplary contribution to the paradigm with his book Kuna Ways of Speaking (for another such attempt see Senft, 2010). Sherzer presents an ethnography of speaking for the Kuna people (who live in the region of San Blas on the Caribbean coast of Panama) in the form of a typology of their ways of speaking that are expressed in specific metalinguistically differentiated varieties and which are manifest in a number of genres or text categories. Sherzer (1983, p. 13) points out that "all Kuna speaking can be viewed as highly adaptive and strategic, finely attuned to contexts of usage and able to change in order to meet challenges from both within and without Kuna society."

\section{Pragmatics and sociology}

In the 1960s and 1970s the research of three North American sociologists had a strong impact on the understanding of human everyday face-to-face interaction in 
general and on the understanding of communicative behavior and language use in particular-especially in conversation.

Erving Goffman's research focused on social interaction, like the presentation of self in everyday life, social encounters, and forms of talk. He shows that social interaction is guided and regulated by normative rights and obligations and thus proposed to call this subarea of sociology "the interaction order." Goffman's microanalyses of social interaction, like, for example, "service transaction" (Goffman, 1983), provided deep insights into the complex structural properties of human interaction in social situations. Social interaction is a social institution with its own rules and orders that constitute a kind of syntax which regulates interactional rights and obligations. Goffman showed that these rules-which also control the order of actions in interaction-are based on social contract and consensus, that is, on the social order constitutive for the interactants' community. Interactions are rooted in, and dependent on, specific contexts and create (new) contexts at the same time. Participants in copresent interaction behave as players in a ritual game. They permanently monitor and analyze each other's forms of behavior; they make inferences regarding their own and the other's motivations, intentions, and self-presentation; and they frame their encounters and permanently (re)negotiate, (re)construct, and (re)frame their roles as well as the interaction situation during these encounters, thus affirming and protecting their dignity-their face-to maintain the ritual and moral order of social life. Thus, "the notion of a conversation encounter does not suffice in dealing with the context in which words are spoken ... the whole social situation, the whole surround, must always be considered" (Goffman, 1981, pp. 144-146).

Harold Garfinkel investigated the sociology of daily life in a specific framework for which he coined the label "ethnomethodology." Garfinkel focuses his research on how ordinary members of a society or community use commonsense practices as means and (ethno)methods of practical reasoning to constitute, understand, and make shared sense not only of the common context and the specific circumstances of their actions, but also of their social world.

In his famous "breaching experiments" Garfinkel instructed students to have an ordinary conversation with a friend, but then to insist that this friend clarifies commonplace remarks, like in the following example (Garfinkel, 1967, p. 44):

The victim waved his hand cheerily.

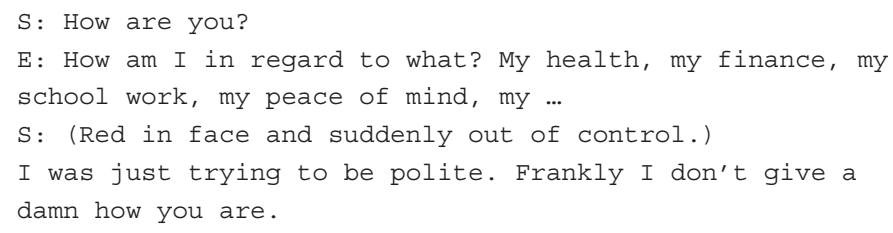

Garfinkel's (1967, pp. 36-37) explicit aim with these experiments was to make commonplace scenes visible by starting with familiar scenes and then make trouble. These experiments revealed that people engaged in social interaction hold themselves and one another morally accountable for the work they have to do to make sense of their (inter)actions and circumstances. 
Harvey Sacks developed the field of "conversation analysis" (CA) in close cooperation with Emanuel A. Schegloff and Gail Jefferson. Sacks was convinced that studying conversations-the actual and basic naturally occurring forms of language use in specific situations and contexts-would provide not only important insights into the details of actual events, but also into the speakers' practical commonsense knowledge and reasoning manifest in their conversational practices. First analyses of telephone conversations focused on the systematics of the organization of turn-taking for conversation in which the speakers co-construct meaning and social action, on how speakers manage to regulate who is speaking next and when, and on the sequential order of social actions and activities during conversation. The following general features observed in conversations are crucial for the CA approach (see Sacks, Schegloff, and Jefferson, 1974, pp. 700-724):

- The number of speakers involved in a conversation varies; speaker-change takes place.

- Usually one party talks at a time; it is common that more than one interactant speak at a time, but these occurrences are rather brief.

- Speakers try to avoid overlaps and to minimize gaps between turns. Turn order and size vary.

- The length of a conversation, its topics, and the turn distribution is not specified in advance.

- Talk can be continuous or discontinuous.

- Speakers use turn-allocation techniques: a current speaker may select a next speaker or parties involved in the conversation may self-select in starting to talk.

- Turns consist of turn-constructional units (TCUs) like, for example, a word, a clause, or one or more sentences that are recognized by their interactants as meaningful. At the end of a TCU a next speaker may take a turn or the current speaker may produce a next TCU. That is to say, ends of TCUs are not only turn-completion points (TCPs), but also transition-relevance places (TRPs).

- Problems that arise during conversation can be repaired by the interactants.

Research within the CA paradigm on turns and turn-taking, gaps and overlaps, repair, action organization or sequencing etc. illustrates that conversation is an emerging, yet highly-and probably universally-ordered activity "in which participants co-construct meaning and social action in an exquisitely timed choreography of interlocking communicative moves" (Mark Dingemanse, personal communication); the understanding of the meaning of these moves in specific speech communities, however, requires cultural knowledge.

\section{Outlook}

In his textbook Anthropological Linguistics William Foley (1997, p. 29) explicitly states that "the boundary between pragmatics and anthropological linguistics or sociolinguistics is impossible to draw at present." Thus, topics like "language, social class and 
socialization" as well as the concept and manifestations of "language ideologies" should ideally be discussed in an entry like this. However, for reasons of length this could not be done here; for a discussion of these topics see Senft (2014).

It should also be noted that despite claims of universality made by many theorists in pragmatics, such as Searle, Grice, and others, a number of linguists strive to emancipate their research in pragmatics from established Western (mostly Anglo-American) paradigms with their theoretical orthodoxies in the field, because they realize that these theories constrain-and in many cases are also inadequate for-describing and analyzing language use and multimodal interaction especially in non-IndoEuropean languages. These attempts are manifest for example in the "emancipatory pragmatics" movement with colleagues like Sachiko Ide and Yasuhiro Katagari as key representatives (see Hanks, Ide, and Katagiri, 2012).

\section{Acknowledgments}

This entry is based on portions of Senft (2014). The author would like to thank Routledge for the permission to use this material.

SEE ALSO: Action and Agency; Anthropology; Behavior, Behaviorism, and Behavioral Sciences; Cognition; Communication Theory and the Disciplines; Community; Collaboration and Cooperation; Cultural Studies; Culture; Ethnography; Ethnomethodology; Expression; Face-to-Face Communication; Goffman, Erving; Interpersonal Interaction; Linguistics; Meaning; Media Sociology; Nonverbal Communication; Philosophy; Psychology; Relativism; Ritual; Sapir, Edward; Semantics; Social Construction of Reality

\section{References and further readings}

Austin, J. L. (1962). How to do things with words. Oxford, UK: Clarendon.

Basso, E. B., \& Senft, G. (2009). Introduction. In G. Senft \& E. B. Basso (Eds.), Ritual communication (pp. 1-19). Oxford, UK: Berg.

Bühler, K. (1934). Sprachtheorie: Die Darstellungsfunktion der Sprache. Jena, Germany: Fischer. Eibl-Eibesfeldt, I. (1989). Human ethology. New York, NY: De Gruyter.

Foley, W. (1997). Anthropological linguistics: An introduction. Oxford, UK: Blackwell.

Garfinkel, H. (1967). Studies in ethnomethodology. Englewood Cliffs, NJ: Prentice Hall.

Goffman, E. (1981). Forms of talk. Oxford, UK: Blackwell.

Goffman, E. (1983). The interaction order. American Sociological Review, 48, 1-17.

Grice, H. P. (1975). Logic and conversation. In P. Cole \& J. L. Morgan (Eds.), Syntax and semantics: Vol. 3. Speech acts (pp. 41-58). New York. NY: Academic Press.

Hanks, W. F., Ide, S., \& Katagiri, Y. (Eds.). (2012). Towards an emancipatory pragmatics. Part two [Special issue]. Journal of Pragmatics, 44(5), 563-708.

Labov, W. (1972). Rules for ritual insults. In W. Labov (Ed.), Language in the inner city: Studies in the black English vernacular (pp. 297-353). Philadelphia, PA: University of Pennsylvania Press.

Morris, C. W. (1938). Foundations of the theory of signs. In O. Neurath, R. Carnap, \& C. W. Morris (Eds.), International encyclopedia of unified science (pp. 77-138). Chicago, IL: University of Chicago Press. 
Pederson, E., Danziger, E., Wilkins, D., Levinson, S. C., Kita, S., \& Senft, G. (1998). Semantic typology and spatial conceptualization. Language, 74, 557-589.

Sacks, H., Schegloff, E. A., \& Jefferson, G. (1974). A simplest systematics for the organization of turn-taking in conversation. Language, 50, 696-735.

Searle, J. R. (1969). Speech acts: An essay in the philosophy of language. Cambridge, UK: Cambridge University Press.

Searle, J. R. (1976). A classification of illocutionary acts. Language in Society, 5, 1-23.

Senft, G. (2010). The Trobriand Islanders' ways of speaking. Berlin, Germany: De Gruyter Mouton. Senft, G. (2014). Understanding pragmatics. London, UK: Routledge.

Seuren, P. A. M. (2009). Language from within: Vol. I. Language in cognition. Oxford, UK: Oxford University Press.

Sherzer, J. (1983). Kuna ways of speaking: An ethnographic perspective. Austin, TX: University of Texas Press.

Gunter Senft is senior investigator at the Max Planck Institute for Psycholinguistics in Nijmegen, the Netherlands, and extraordinary professor of general linguistics at the University of Cologne, Germany. His main research interests include Austronesian and Papuan languages, anthropological linguistics, nominal classification, multiverb constructions, pragmatics, and semantics. He is the editor-in-chief of Pragmatics: The Journal of the International Pragmatics Association and editor of the series Culture and Language Use: Studies in Anthropological Linguistics. He has published widely on the language (Kilivila) and culture of the Trobriand Islanders in Papua New Guinea. In 2014 he published the textbook Understanding Pragmatics. 